\title{
Drug supply networks: a systematic review of the organizational structure of illicit drug trade
}

\author{
Gisela Bichler $^{{ }^{*}} \mathbb{D}$, Aili Malm² and Tristen Cooper ${ }^{3}$
}

\begin{abstract}
This study presents a systematic review of research using social network analysis to document the structure of organized crime groups involved in drug trafficking. Our first objective is to determine whether the balance of evidence supports the argument that organized crime groups are loosely structured. Second, we aim to assess the relative importance of targeting individuals high in social capital (structural position) versus human capital (access to resources) in efforts to disrupt operations. Examining 34 studies, describing 54 illicit drug supply networks, we find five implications for anti-drug policy, and propose seven recommendations to facilitate meta-analysis and improve cross-network comparison.
\end{abstract}

Keywords: Dark networks, Organized crime, Drug trafficking, Illicit drug supply, Social network analysis, SNA

\section{Background}

Qualitative research examining organized crime groups, with an emphasis on drug trafficking activity, finds varying group structure within a loosely connected trade network. While these assessments are useful, there is little consistency in how authors operationalize organizational forms (as noted by Dorn et al. 2005), in part because these analyses are unable to map the actual structure of the group. Deepening our understanding of how illicit drug markets operate is pivotal to designing effective policy and crime control strategies. If structure varies, perhaps by market niche, drug trafficked or group characteristics, then we must tailor crime control efforts so they target the vulnerabilities of specific types of operations. Structure matters.

To standardize our descriptions of criminal group structures and begin the process of verifying the suppositions generated by qualitative research, scholars are turning to social network analysis (SNA). Capitalizing on a suite of empirical tools-theory, metrics, and

\footnotetext{
*Correspondence: gbichler@csusb.edu

${ }^{1}$ Department of Criminal Justice, Center for Criminal Justice Research, California State University, San Bernardino, 5500 University Parkway, San Bernardino, CA 92407, USA

Full list of author information is available at the end of the article
}

analytics-crime scientists use SNA to document the interdependence among actors involved in drug trafficking. Rather than describing a group in general terms using researcher generated typologies, SNA studies use common metrics to characterize group structure, pinpoint specific actors and groups that control key market activities, i.e., importing drugs, laundering proceeds, etc., and identify individuals positioned to reestablish trade activity when central figures are removed. Thus, SNA provides an opportunity to re-examine what we think we know about market structure from a fresh perspective.

Examining SNA research of drug trafficking organizations, this systematic review of 34 published studies, describing 55 trade networks, is the first to synthesize what we currently know about the structure of illicit drug trade. We begin with a brief overview of landmark qualitative research and describe how SNA can contribute to the study of the organizational structure of crime groups. Then, we outline our document search protocol, and detail our methods. The results are partitioned into two sections. First, we examine network structure and find evidence confirming the idea that groups and drug markets are loosely organized and that groups have identifiable central figures. Second, we consider the relative importance of social capital (e.g. network position) 
and human capital (e.g. access to resources), confirming a correlation between social and human capital and that network vulnerabilities, representing key persons, are identifiable. We conclude with a discussion of the implications these findings have for crime control policy and provide direction for future research to facilitate metaanalyses and improve cross-network comparison.

\section{Structure of drug trafficking groups Group structure}

Contrary to media inspired conceptualizations of organized crime, qualitative research investigating the configuration of drug trafficking organizations finds varying group structures within a loosely connected trade network (for a review of some of this literature see Natarajan and Hough 2000). While a thorough review of the field is beyond the scope of the present study, a number of seminal research projects inform hypotheses about the structure of groups involved in illicit drug markets.

Adler (1985) showed early on that organized crime groups tend to operate similar to legitimate business. Using ethnographic methods, she revealed that drug trafficking operations are loosely structured, often involving informal agreements among market participants. Arguing that market structure is to some extent dependent upon the source of the drug handled; the specialized importation of foreign drugs requires fewer people and less formal structure than domestic drug production. Domestic drug production is also more likely to mimic a legitimate organization due to local competition.

Interviewing 40 incarcerated high-level cocaine and marijuana traffickers, Reuter and Haaga (1989) discovered that their networks typically take the form of small partnerships consisting of temporary and dynamic coalitions of dealers. Acknowledging methodological limitations associated with the sample, Reuter and Haaga make several key observations about the markers of 'success' in the industry that are of relevance to the present study. (1) There are few barriers to getting involved in the market; namely, access to capital, effort, luck, and use of violence are not required for success. (2) Traffickers are not limited to working regionally-the market is national. In the wholesale market, experience and the willingness to make and take opportunities limits involvement. (3) Large or long lasting networks exist, but they are not required for success in high-level drug operations.

To this point, Eck and Gersh (2000) examined 620 cases gathered from federal, state, and local drug investigations in the Washington-Baltimore High Drug Trafficking area (W/B HIDTA) from 1995 to 1997. The results show that $60.4 \%$ of cases involved individuals or actors conspiring with a loose-knit association. Further, of the 39.1\% involved in some form of a criminal organization, most
(66.7\%) comprised groups of less than 21 people. After studying operations in greater detail (e.g., communications patterns, transactions, and security), the authors conclude that drug trafficking more closely resembled a cottage industry of small, somewhat temporary sets of people, and that there were few instances of large, hierarchically-organized distribution networks.

Qualitative studies of drug operations trafficking crack, cocaine, and heroin throughout the 1990s and 2000s found similar results. For instance, Dorn et al. (2005) reviewed upper-level drug trafficking literature, concluding that drug traffickers are diverse and driven by different motivations. These differences are reflected in group structure and vulnerability: business criminals motivated by profit are more likely to have a durable core with several connections to different groups and individuals than ideologically motivated offenders (Dorn et al. 2005). In his interviews with Colombian, drug cartel informants, Kenney (2007) shows that trafficking networks are flexible and react to opportunities and constraints by expanding and contracting in size and reach. Research by Spapens $(2010,2011)$ also supports these findings. He shows that drug market monopolies are rare and difficult to maintain. He highlights the differences between legitimate and criminal markets, focusing on the need for trust in illicit business.

This literature led to the following working hypothesis: while several structures exist, most operations are loosely connected networks that can quickly react to shifting market conditions. What is not clear from this body of work, however, is whether mapped networks exhibit loose connectivity and to what extent this structure pertains to specific, clearly defined groups of actors, and to what extent these patterns characterize general market structure. A key issue in understanding the form and function of a network is to establish membership boundaries, because including peripheral individuals who are not really part of the group can significantly alter how we describe the network. A dense, cohesive group with a single leader will appear to look like a loosely connected set of clusters if people linking groups together are also included. Thus, it is important to consider group structure (within a definable crime group) and market structure (connections between different groups in a distribution chain) independently-it is possible that within group structure can be hierarchical even when the market as a whole exhibits the properties of a loosely connected network. Moreover, with each author developing their own typology of group structure it is difficult to conduct the cross-study comparisons needed to establish general patterns. Standardized metrics are needed to describe the nature and distribution of organizational structures. 


\section{Role differentiation}

The importance of role differentiation by activity (i.e., fetching precursor drugs versus cooking methamphetamine) or market niche (i.e., cross-border smuggling versus wholesale supplying) also emerges from the review of qualitative research. Variation in organizational structure means that disruption efforts will need to be tailored to the type of operation and the inherent resilience of the group structure. For instance, through extensive interviewing of 296 subjects involved in crack, cocaine, and heroin distributions, Johnson et al. (2000) found evidence of role differentiation in response to police attention: countermoves involved parsing drug market activities into specific tasks, (e.g., separating holders, transporters, deliverers, money counters, versus guards, etc.) in order to be flexible and resilient to crime suppression activities. Their research also uncovered that market niches, such as low-level distribution, dealing, and upper-level distribution, show variation in organizational structure. This suggests that market forces at each level of trade impose unique constraints upon individuals engaged in drug trafficking.

Even within money laundering, a function we generally recognize as a relatively specialized facet of drug trafficking, we find evidence of the varied, and thus flexible, nature of operations (Schneider 2010; Soudijn 2012). For example, studying 31 Dutch cases involving large-scale cocaine importation, Soudijn (2014) discovered that only half of the investigations (14 cases) involved people providing financial services typically associated with money laundering. Contrary to conventional wisdom, however, the study uncovered a wide range of financial activity and financial facilitators were not accountants or lawyers; rather, individuals were involved in either sending money between countries (e.g., smuggling cash and hawala banking) or they participated in activities to give money a legal appearance, such as investing in the legal economy. Though not commented on by Soudijn (2014), this suggests human capital-individual resources and skill sets-influences whether, and in what capacity, someone is involved in drug market activities. Human capital may also differentiate leaders and critical personnel from easy to replace subordinates.

More recently, Natarajan et al. (2015) examined 89 organizations uncovered through major investigations of the Drug Enforcement Administration (50 cases constituted the nation-wide sample) or prosecuted in New York City (39 cases) from 1997 to 2007 with the aim of testing a system of classifying groups along two dimensions-organizational structure and tasks. Most notably, they find that data source impacts structural variation. For instance, when using New York City data, 12.8\% of groups have a corporate organizational style and $30.1 \%$ were communal businesses, whereas, federal cases tended to involve corporate $(54 \%)$ or communal businesses (42\%). Where corporate organizational style includes a formal hierarchy and division of labor and communal businesses are comprised of members linked by at least one common characteristic, i.e., religion, nationality, neighborhood, or race. Additionally, 41\% of New York cases and $62 \%$ of federal cases concerned groups involved in multiple niches (e.g., smuggling, wholesale, and regional distribution). Again, having a flexible, informal structure and being involved in a range of activities speaks to the potential impact that the collective resources and individual human capital play in shaping operational structure.

These studies suggest that drug trafficking is comprised of entrepreneurs exploiting their social and human capital. Our second working hypothesis follows from this idea. The hypothesis states, varying structural properties emerge for different types of market involvement and that market leaders and critical personnel (central individuals) are those with the greatest human capital. Soudijn (2014) and Natarajan et al. (2015), however, raise the concern that what we think we know about organizational structure is to a large part, pre-determined by the focus of and resources deployed during investigations, as well as the prosecutorial discretion of attorneys at the local and federal levels. Thus, we may find that variation in the predominance of central individuals is contingent on the scope of the study and source of information.

\section{Network analysis of trafficking networks}

While SNA-oriented study of organized crime is relatively new, the material advantage of using network science to study criminal organizations was lauded over two decades ago [see for example Jackson et al. (1996) and Sparrow (1991)]. Because we are still in a relatively nascent stage of development, crime scientists are still working through SNA theory and metrics to identify the most appropriate mechanisms to test our ideas about the structure of crime groups. With this caveat in mind, two themes dominate our efforts to map the structure of illicit drug trafficking.

\section{Criminal network structures}

Crime scientists working with SNA have come to view criminal networks differently from other social networks because they operate in hostile environments. For instance, Morselli writes, "Criminal networks are not simply social networks operating in a criminal context. The covert settings that surround them call for specific interactions and relational features within and beyond the network $(2009 ; 8)$." With various agents of the criminal justice system working to constrain illicit trade, 
individuals profiting from criminal enterprise must work in secrecy, under a cloak of invisibility; whereas, legitimate trade activity may organize to maximize the efficiency of operations. This ongoing challenge shapes how the group, and overall market, operates. As stated in our first working hypothesis, qualitative investigations suggest that drug operations are primarily loosely connected networks capable of rapid change in response to shifting market conditions. While direct SNA metrics of these concepts do not exist, we can explore comparable concepts of network density (or sparseness) and centrality, and what this means for operational structure.

Figure 1 illustrates the difference between dense and sparse operations and introduces two types of central positioning-hubs and brokers [(see Borgatti and Everett 1992, 2006) or for a more information about network centrality and associated metrics visit https:// en.wikipedia.org/wiki/Centrality or http://www.faculty. ucr.edu/ hanneman/nettext/C10_Centrality.html]. This begins our discussion of how operational structures may indicate a preference for efficiency or secrecy (security). Note that in this hypothetical example, the circles represent people involved in the manufacture and trafficking of methamphetamine and the arrowheads indicate the flow of communications through the network.

If we look at person 6 , denoted by a grey circle, in Fig. 1a, we see their position in the network allows them to exchange information with most others in the network. This information exchange is efficient and may be quick as there are few intermediaries required to reach other group members. In this example, density is high, meaning that most people connect directly to each other.

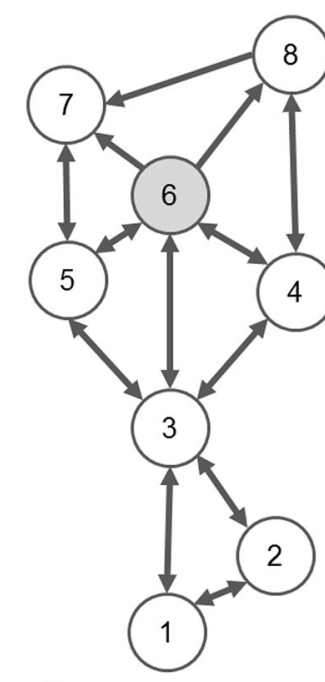

a dense, less centralized structure

Fig. 1 Network structures characterizing security and efficiency
Higher network density positively effects the network's efficiency, provided messages take direct paths through the network. Arguably, this structure may also increase trust among individuals in the network [see Coleman (1988) and Granovetter (1981) for more details on trust and network closure]. An additional benefit is that with the removal of any individual, the group would continue to function: it is highly resilient to attack because of its high level of interconnectivity. While more efficient and resilient to attack, the structure reduces operational security. This means the network is not "secure" against efforts by law enforcement to uncover information about operations. For example, if we arrest person 6 , or anyone else for that matter, they have knowledge of all group members and could implicate everyone in an investigation. Compare this network structure to Fig. 1b; here, we see that if person 6 were to act as an informant, they could only implicate the person they receive information from, person 3, and the person they transmit information to, person 8 . The network is relatively secure, because it is sparse and few connections exist among people in the group. The drawback is that rebuilding operations can be lengthy and difficult when crime control efforts remove a centrally placed individual.

Sparse, or loosely connected networks, typically include individuals centrally positioned as hubs and brokers. Individuals with a lot of direct connections (such as person 3 in Fig. 1b), relative to others in the network, are hubs. Theoretically, we consider hubs to have the greatest degree of influence in the network; they can directly share information with more people than anyone else can. Brokerage is a different idea about central positioning-brokerage positions enable someone to control the flow of information between any randomly selected pair of other actors in the network. Returning to Fig. 1a, since any effort to communicate with person 1 or 2 must go through person 3, person 3 is in a better position to broker information within the group. These structural positions offer a strategic advantage for crime control when networks are sparse: disruption efforts that aim to remove central actors, namely hubs and brokers, stand the greatest chance to disrupt network functions.

\section{Social and human capital}

Another social network argument is that individuals positioned with ties to unique clusters of people have greater social capital (Burt 1992, 1997). Bridging different groups of people has a strategic advantage; individuals become indispensable to the overall group because they alone "hold" the group together and they ensure that they are the first to hear new information as it passes through the network. When combined with human 
capital, that is having unique skills or access to resources, a well-equipped bridge has great potential to maximize their success. When applied to organized crime groups and drug markets, we may hypothesize that varying structural properties emerge for different types of market involvement. Owing to the idea that some activities are more important to operations (e.g., money laundering and smuggling) and that, market leaders and critical personnel (central individuals within a group or connecting different groups) are those with the greatest human capital.

As illustrated in Fig. 2a, individuals 3 and 6 have equivalent social capital. They each have efficient connections, meaning they established a single relation with each of three different clusters of people. Since the clusters do not have other connections joining them to the other groups of people, individuals 3 and 6 have unique positions. Sitting between several subgroups, they have the opportunity to reap the most benefit from the information they access from each cluster. This network position presents opportunities to use or act on information first and may serve to enhance the success of persons 3 and 6 . In doing so, their actions may enhance the overall success of the entire network. Notably, if we factor for the ability to act on this information, meaning that we consider the individual attributes and resources of each person, we may discover that despite having similar social capital, person 3 (the meth cook as indicated in panel b), has greater human capital, and so, may be better able to use their social capital to their advantage. The argument being, couriers have a less specialized skillset making person 6 easy to replace, whereas with greater individual resources, the meth cook would be harder to substitute. In this scenario, positional advantage is not sufficient; it is only when the information benefit accrued from social position intersects with human capital that material advantages are likely realized.

\section{Present study}

Adapting the working hypotheses derived from qualitative research to fit within an SNA framework, we sought to answer two sets of questions.

1. Does the SNA literature identify specific network structures common to drug trafficking organizations that are consistent with the findings of qualitative research? If so, is there a difference between group structures and market structures? Moreover, given methodological shortcomings, what strategic implications can we derive from these findings to aid crime control efforts aimed at disrupting drug trade?

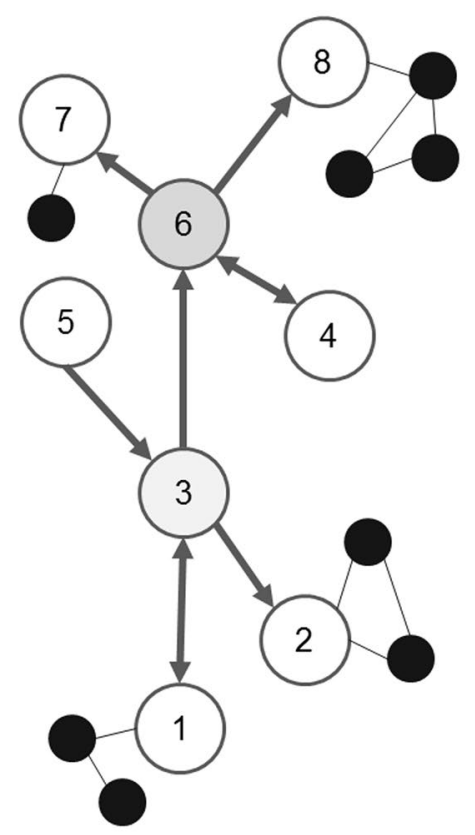

a social capital associated with links to unique groups

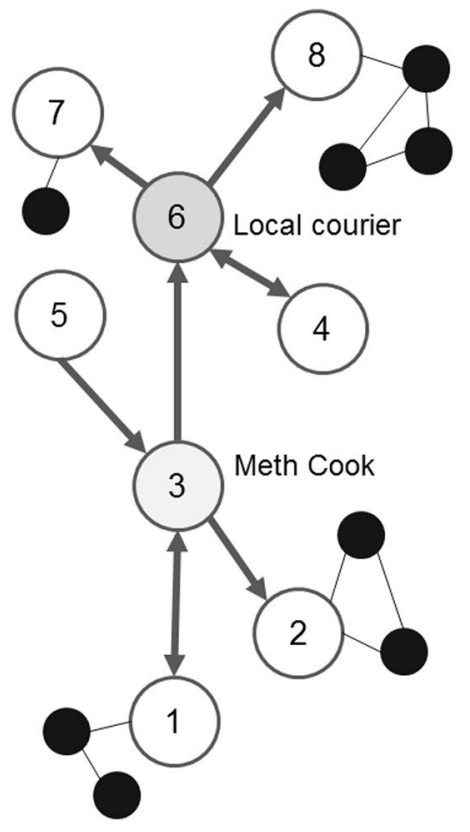

b human capital enhances positional importance

Fig. 2 Network structures characterizing social and human capital 
2. What is the relative importance of social capital (position within the network) and human capital (access to unique resources and skills) in determining who are the critical actors or groups within an illicit drug market? By using such information, do crime control efforts gain an advantage in efforts to disrupt market activity? Do the methodological shortcomings associated with studying criminal networks influence these findings?

\section{Methods}

\section{Source identification}

To ensure our search protocol was systematic, thorough, and efficient (fewest number of false positives), we identified an optimal set of search terms through an iterative process using a notable hit weight selection criterion. ${ }^{1}$ To calculate the notable hit weight for each set of possible search terms we divided the number of articles found on Google Scholar written by notable authors ${ }^{2}$ by the total number of matches identified. We assume that a search term or phrase that returns a high yield of materials produced by known, active scholars in the field will likely be more effective in uncovering similar types of research produced by other authors with a smaller body of work. Starting with a preliminary set of potential terms, ${ }^{3}$ drawn from the keywords listed in articles written by notable authors, we systematically removed all poorly preforming items. For instance, we removed the search term "co-offending" because it generated too many false positives-few articles pertained to drug trafficking networks. As reported in Table 1, this process resulted in six best preforming sets of keywords. Next, we tested various keyword combinations to build an optimal set of terms, settling on "Illicit drug network structure analysis trafficking" + "network analysis" which achieved a notable hit rate of 90:1,560, a value that was 2.8 standard deviations above the mean of all other tests. ${ }^{4}$

\footnotetext{
${ }^{1}$ As aptly pointed out by one of the reviewers, systematic reviews are typically inefficient, partly to ensure that the search uncovers the population of studies or as much of the population as possible. Given the high volume of materials uncovered in preliminary tests of search terms that did not include the type of study we sought, the research team decided to develop a process to improve search efficiency without losing our ability to identify obscure publications.

2 The list of scholars known to use social network analysis in studies of drug trafficking groups includes: Gisela Bichler, Martin Bouchard, David Bright, Francesco Calderoni, Paolo Campana, Aili Malm, Carlo Morselli, and Mangai Natarajan.

3 The original terms to describe the research were: drug trafficking, organized crime groups, cartel, social network analysis, group structure, drug markets, co-offending networks, and illicit drug distribution.

4 This means that there were potentially 90 useful documents within a pool of 1560 items uncovered in the key word search.
}

We used EBSCO Host, JSTOR, Simon Fraser University's Fast Search, and Google Scholar to search for sources. Each document was scanned against a set of inclusion criteria: the document must be published in English, with a scholarly outlet, after 1990, and contain social network analysis of at least one drug trafficking network using one or more recognized social network metric and/or analytic procedure. Moreover, the specified focus of the research had to be drug trafficking; articles looking at the overall structure of organized crime groups (e.g., Campana 2011; Varese 2011, 2012) were not included as all legitimate and multiple types of illicit activity were combined into a single network and our aim was to investigate only the portion of their operations involved in illicit drug trafficking. Each source appearing to satisfy the criteria based on a scan of the title, abstract and results was retained, and later read closely to confirm eligibility. Additionally, the research team examined the references of all sources for additional articles.

Figure 3 illustrates the screening process used to identify suitable studies. Thirty-four sources met the inclusion criteria (see reference section "Sources for systematic review"). Of note, many potential items were excluded due to a lack of network statistics: we were unable to include several important studies discussing the utility of SNA or theoretical concepts of interest to the study of dark networks (e.g., Kenney 2007; Spapens 2010) and seminal inquiries into group structure using qualitative methods (e.g., Natarajan et al. 2015; Soudijn 2014; Spapens 2011), because they did not present actual network metrics.

\section{Description of sources}

Of the 34 studies identified, $76 \%$ were case studies; where $41 \%$ focus on the workings of a particular group and $35 \%$ examine the distribution chain involving a central group but including all of their associations to other groups (see Table 2). About $18 \%$ of the studies investigated a population of actors known to be involved in drug-related criminal enterprise. ${ }^{5}$ Concerning geographic coverage, most research examined groups with central operations in North America or the Mediterranean. Notably, only one

\footnotetext{
${ }^{5}$ Research investigating a population of individuals known to be involved in drug trafficking typically involves a data mining process wherein the network generated includes everyone known to police. This often involves consolidating information from different data systems. From this point, selection criteria are applied to hone the file, i.e., for a co-offending relation to exist the individuals must be known to commit at least two crimes together. This contrasts with case study approaches, which define a group of individuals, usually by known membership or coactivity with known members of a group.
} 
Table 1 Sample of results from the search term generation process

\begin{tabular}{|c|c|c|c|}
\hline Search terms & Results & Total hits for notables & Weight \\
\hline \multicolumn{4}{|l|}{ Search term development (identifying terms) } \\
\hline Illicit drug distribution & $\sim 120,000$ & 145 & 0.001208 \\
\hline Cartel & $\sim 165,000$ & 26 & 0.000158 \\
\hline Drug trafficking networks & $\sim 525,000$ & 127 & 0.000242 \\
\hline SNA & $\sim 258,000$ & 41 & 0.000159 \\
\hline Organized crime groups & $\sim 1,250,000$ & 185 & 0.000148 \\
\hline Group structure & $\sim 5,990,000$ & 215 & $3.58 \mathrm{E}-05$ \\
\hline \multicolumn{4}{|l|}{ Modification of terms (building term sets) } \\
\hline Co-offending drug network structure analysis & $\sim 960$ & 80 & 0.083333 \\
\hline Illicit drug network structure analysis trafficking & $\sim 30,800$ & 143 & 0.004643 \\
\hline Illicit drug network structure analysis & $\sim 67,800$ & 143 & 0.002109 \\
\hline Structure drug trafficking networks & $\sim 112,000$ & 155 & 0.001384 \\
\hline Network analysis drug trafficking & $\sim 200,000$ & 161 & 0.000805 \\
\hline Drug markets network structure analysis & $\sim 295,000$ & 192 & 0.000651 \\
\hline \multicolumn{4}{|l|}{ Final terms chosen } \\
\hline Illicit drug network structure analysis trafficking + "network analysis" & $\sim 1560$ & 90 & 0.057692 \\
\hline
\end{tabular}

The average weight of search terms was 0.011735999 with a sample standard deviation of 0.016402695

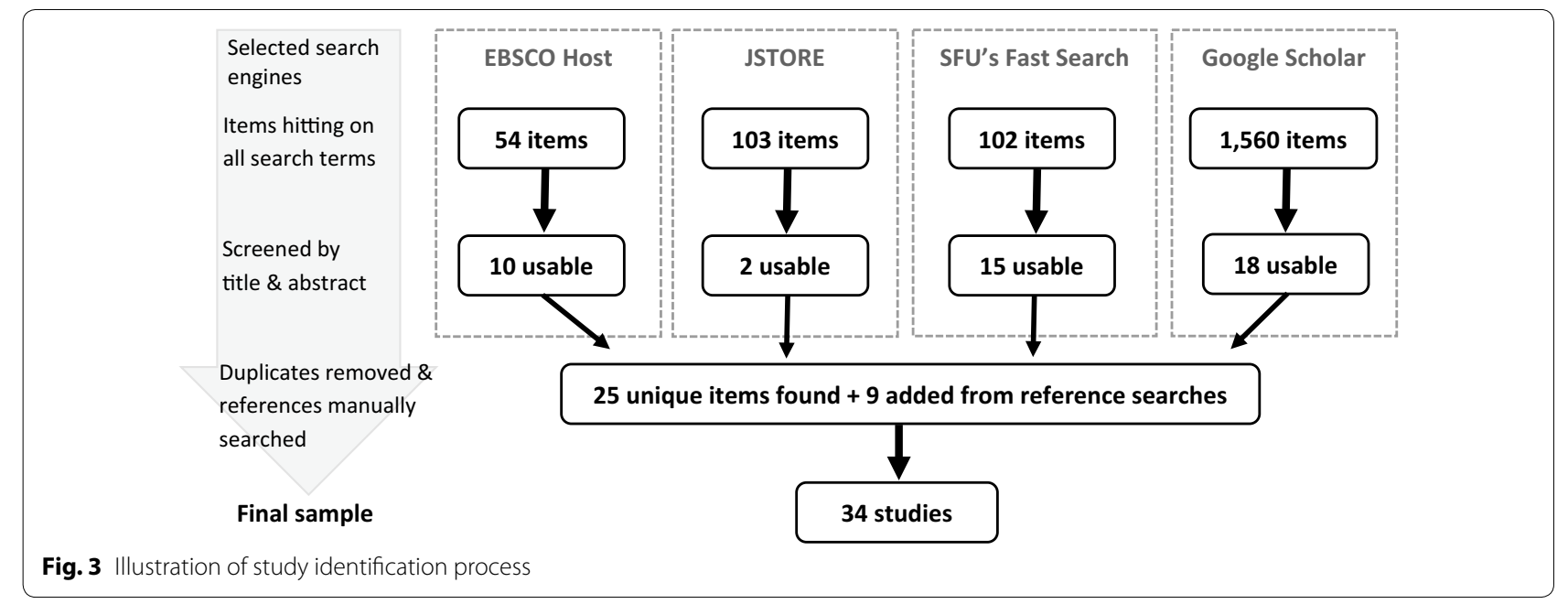

study sought to examine a global network (not reported in the Table 2). Collectively, most of these studies examine organized crime groups involved to some extent in the trafficking of cocaine. While we searched articles from 1990 to 2015, 71\% of sources were published since 2010. As reported in Table 2, most research aims to describe networks or explore research questions about the structure of the drug trafficking organization, using descriptive statistics or simple hypothesis tests. About $79 \%$ of studies are cross-sectional, with data aggregated from police intelligence information. Publication venues tended to be peer review (82\%) and only $21 \%$ of studies were funded.

\section{Sample description}

In this study, we originally intended to use the network as the primary unit of analysis instead of published studies. ${ }^{6}$ The 34 sources identified describe 55 networks, some of

\footnotetext{
${ }^{6}$ As noted by one of the reviewers, in systematic reviews and meta-analyses, there is a parallel distinction between using findings and studies. We argue that networks (i.e. reviews focused on research findings) are appropriate because in much of the scientific literature, a single report will describe, and often systematically compare, the structure of multiple networks. This means that if the article were the unit of analysis, the research team would have to select one network for inclusion in the study. Choosing between networks leaves the current project open to the criticism that researcher bias tainted the selection process. Thus, the research team decided to use all networks described in each study. As the reader will learn shortly, a problem occurred forcing us to report on studies.
} 
Table 2 Publication details and methods used in the 34 network studies on drug trafficking organizations

\begin{tabular}{|c|c|}
\hline Description of methods & Percent \\
\hline \multicolumn{2}{|l|}{ Study focus } \\
\hline Case study—group focus & 41.2 \\
\hline Case study—distribution chain & 35.3 \\
\hline Population/data mining & 17.6 \\
\hline Egonet distribution chain & 2.9 \\
\hline Multiple types & 2.9 \\
\hline \multicolumn{2}{|l|}{ Coverage } \\
\hline Canada or US & 45.5 \\
\hline Spain, Italy, or Greece & 24.2 \\
\hline Australia & 12.1 \\
\hline Colombia or Mexico & 9.0 \\
\hline UK or the Netherlands & 9.0 \\
\hline \multicolumn{2}{|l|}{ Drug Market } \\
\hline Multiple (includes cocaine) & 48.4 \\
\hline Cocaine & 27.3 \\
\hline Methamphetamine & 15.2 \\
\hline Cannabis & 6.1 \\
\hline Heroin & 3.0 \\
\hline \multicolumn{2}{|l|}{ Group type } \\
\hline Independent (no formal designation) & 38.2 \\
\hline Mafia or cartel & 23.5 \\
\hline Assorted (mixed) & 23.5 \\
\hline Street gang & 8.9 \\
\hline Outlaw motorcycle gang & 5.9 \\
\hline \multicolumn{2}{|l|}{ Publication date } \\
\hline 2000-2009 & 29.4 \\
\hline 2010-2015 & 70.6 \\
\hline \multicolumn{2}{|l|}{ Research aim } \\
\hline Exploring research questions & 47.1 \\
\hline Descriptive & 35.3 \\
\hline Testing formal hypotheses & 11.8 \\
\hline Disruption simulation/assessment & 5.9 \\
\hline \multicolumn{2}{|l|}{ Level of statistical analysis } \\
\hline Low (descriptive only) & 47.1 \\
\hline Medium (e.g., simple hypotheses tests) & 41.2 \\
\hline High (e.g., advanced simulation, multivariate analysis) & 11.8 \\
\hline \multicolumn{2}{|l|}{ Analytic framework } \\
\hline Cross-sectional analysis & 79.4 \\
\hline Dynamic analysis & 20.6 \\
\hline \multicolumn{2}{|l|}{ Primary data source } \\
\hline Police intelligence/investigative files & 76.5 \\
\hline Court records/transcripts of evidence & 14.7 \\
\hline Books (investigative journalism, auto-biography) & 5.9 \\
\hline Customs seizures & 2.9 \\
\hline \multicolumn{2}{|l|}{ Funding } \\
\hline None specified & 79.4 \\
\hline Federal grant & 11.8 \\
\hline Private or university-based & 8.8 \\
\hline Publication venue & \\
\hline
\end{tabular}

Table 2 continued

\begin{tabular}{lc}
\hline Description of methods & Percent \\
\hline Peer review journal article & 82.4 \\
Chapter & 14.7 \\
Conference paper & 2.9 \\
\hline
\end{tabular}

which are subnetworks based on different extractions. The meta-analytic database constructed for this study included

1. Details about the methods used and the network generation process (e.g., description of data source, a sampling description, time frame, boundary specification, ${ }^{7}$ type of drugs trafficked by the network, and the directionality and valuation of connections $\left.{ }^{8}\right)$;

2. descriptions of each network (e.g., total number of actors in the network, number of connections among them, density, number of components, as well as the average, standard deviation, and degree of centralization for measures of actor positioning); and,

3. specifics about the analysis performed, i.e., whether the analysis was dynamic or cross-sectional, what tests were performed to answer stated research questions or hypotheses, and if they conducted a sensitivity analysis.

Much to our chagrin, there was little consistency in the information reported about each network, few commonalities exist in the analysis conducted, and stated research questions or hypotheses varied widely. For example, one of the most fundamental descriptive statistics to report about a network is density-the number of observed connections in the network relative to the number of links that could be present if all actors connected to each other. Descriptions of only 26 networks $(48.1 \%$ of the networks discussed in the source articles) reported density. The simplest information, the number of actors and links present in the network, was more broadly reported, 85.2 and $53.7 \%$ respectively. This is not particularly encouraging given these details are equivalent to reporting the sample size in other research domains. Common descriptive statistics are even more elusive: only $12 \%$ of the studies report all standard descriptive statistics for each network (e.g., average and

\footnotetext{
7 To build a network, it is essential to predefine who is eligible for inclusion in the "group". This is an important decision in the research process as being overly restrictive or too broad may significantly alter the results.

${ }^{8}$ Directed networks are such that the connections among actors have an inherent directionality because whatever is passing through the network (i.e., drugs, information, and money) flows from one person to another. Moreover, connections can be valued to indicate the amount of something passing between actors, the value of the exchange, or the strength of the relationship. Specifying these details about how the network was constructed is critical as it changes the way we interpret structural statistics.
} 
standard deviation for degree centrality, density, average path length, and number of actors and links) and $24 \%$ of articles report standardized values, required to directly compare different networks. Moreover, studies ranged in methodologies from descriptive core analysis (e.g., study Bouchard and Konarski 2014) to regression models (e.g., study Grund and Densley 2012) to simulation experiments (e.g., study Duijn et al. 2014). Not all is lost, however, as two critical themes emerged from our inspection of network-based studies of organized crime structure; in the results section that follows, we discuss the criminal network structure, specifically the trade-off between efficiency and security, and the relative importance of human capital versus social capital.

\section{Results}

\section{Criminal network structure}

Our first set of research questions examine whether the SNA literature finds specific network structures common to drug trafficking organizations; if there are differences between group structures and market structures; and, whether these structural patterns offer strategic implications to aid crime control efforts aimed at disrupting the illicit drug trade. Of the 34 studies included in this review, 14 examine operational structure in detail (see Table 3) and characterize the research objective as exploring the efficiency and security trade-off. ${ }^{9}$ Networks engaging in illicit activity have to balance the need for efficient business connections and communication with security and secrecy (Baker and Faulkner 1993; study Morselli et al. 2007). Theoretically, this balance is not as important in legitimate, conventional networks (study Duijn et al. 2014). This trade-off might account for operational structures described in qualitative research-the preponderance of loosely structured networks of entrepreneurs.

Across the 15 networks described in these 14 studies, the statistics used fall under two broad categories-centrality and embedding. Centrality measures are marginally more common. Specifically, eight out of 14 (57\%) studies used both degree and betweenness centrality, and

\footnotetext{
${ }^{9}$ Seven other studies (studies Berlusconi 2013; Boivin 2014; Bouchard and Konarski 2014; Calderoni and Piccardi 2014; Canter 2004; Grund and Densley 2012; Hutchins and Benham-Hutchins 2010; Salazar and Restrepo 2011) examine network structure and employ centrality and embeddedness measures, however, significant divergence in research aim and theoretical framework prohibit their inclusion here. With this said, results are included in this section where appropriate, in the text or as a footnote. Of interest to the reader, only one study (study Canter 2004) attempts to use six indices of organizational structure to generate a typology of criminal organizations. This study finds a range of structure from very loose networks with no central figures to highly structured operations. Two factors account for this variation-size of the group and centrality of leadership. Canter (study Canter 2004) concludes that there are three types of criminal organizations-ad hoc groups, oligarchies, and organized criminals, the former exhibiting the smallest group size and the latter being the largest.
}

three studies used closeness centrality. Degree centrality is the count of ties attached to a given individual (Freeman 1979). Individuals with high degree centrality have more connections. Betweenness centrality is the number of times that an individual sits along the shortest path between all others in the network (Freeman 1979), and represents the extent that an individual mediates connections and information. Closeness centrality assesses the ability of an actor to communicate along the shortest path to all others in the network (Freeman 1979). Irrespective of the type of centrality, when networks exhibit lower overall centralization, it means that a smaller portion of the network is dependent on a single actor. Notably, this structural dependence does not necessarily suggest hierarchical control: centralization would only be interpreted as reflecting hierarchical organization if the direction of actor connections indicated chain of command. Overall, the studies show that drug trafficking networks have higher centralization than conventional networks (study Calderoni et al. 2014), simulated networks (study Malm and Bichler 2011), and terrorist organizations (studies: Morselli et al. 2007; Xu and Chen 2008). The studies also show that centralization increases with the threat of law enforcement targeting (Morselli and Petit 2007).

Six out of 14 studies (43\%) reported embedding measures. Statistics measuring how individuals are embedded in larger social structures include density, path length, clustering, efficiency, and transitivity. ${ }^{10}$ Embedding measures are tools that allow social network analysts to contextualize and understand the entire population and how network structure constrains or enables actors in the network. Of note, only two studies combined centrality and embedding statistics to explain the security and efficiency trade-off (studies: Calderoni et al. 2014; Morselli et al. 2007). Overall, the studies show that individuals in drug trafficking networks are more embedded than conventional networks, and less embedded than terrorist organizations, as indicated by lower path length and clustering coefficients (studies: Mainas 2012; Morselli et al. 2007; Xu and Chen 2008).

A group's objectives and operational tempo appear to moderate its network structure. Networks whose primary purpose is to make money tend to favor efficiency (greater density), while networks with more ideological

\footnotetext{
${ }^{10}$ Path length refers to the average geodesic distance (average length of the shortest paths) linking each pair of people in the network; the clustering coefficient captures the extend of clumping (areas of high and low density) in the network; efficiency is a standardized metric (controlling for network size) that captures the non-redundant nature of an individual's connections, meaning that they have ties to unique clusters of people that do not otherwise connect; and, transitivity refers to the occurrence of triadic configurations (sets of three people all connected to each other) relative to intransitive structures (groups of three where there are only two links among actors).
} 


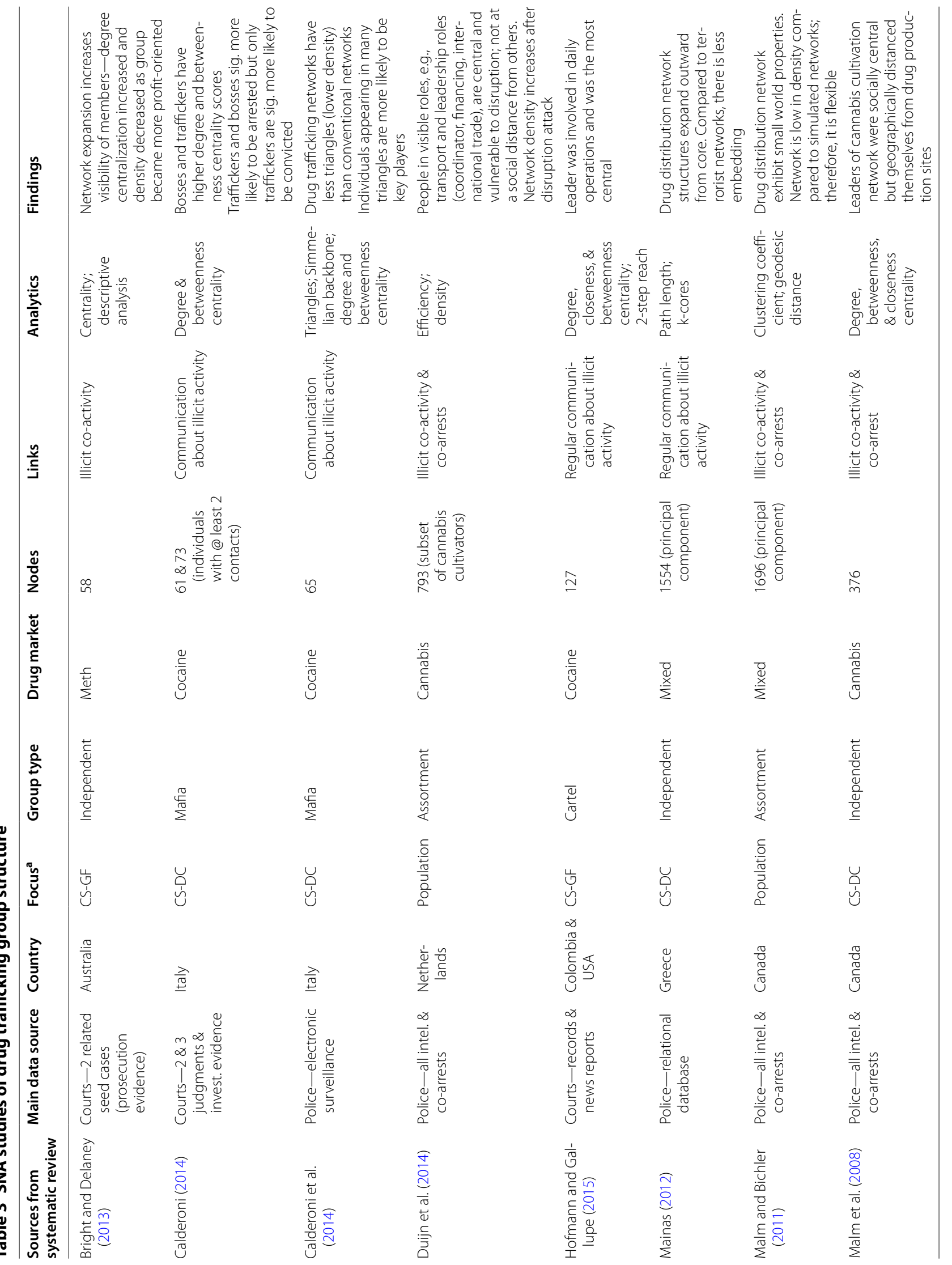




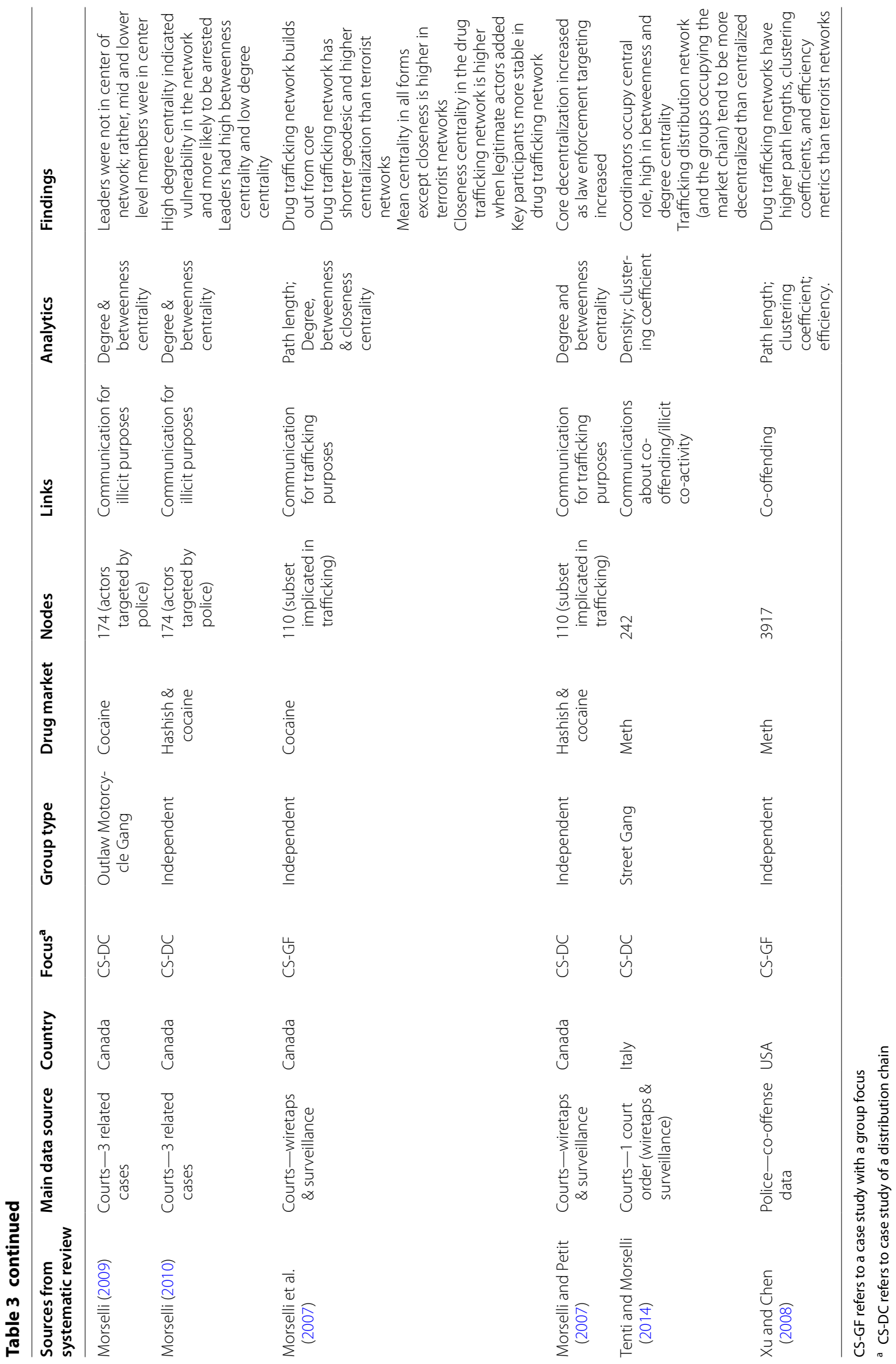


goals or a longer time to act favor sparseness with fewer central actors (studies: Bright and Delaney 2013; Morselli et al. 2007): this finding generally concurs with Dorn and colleagues (2005). Overall, the studies included in this review show that drug trafficking network structure appears to be lower in centralization and density than both legitimate networks (studies: Calderoni et al. 2014; Duijn et al. 2014; Malm et al. 2010) and general cooffending networks (study Duijn et al. 2014), and more centralized and dense than terrorist networks (studies: Mainas 2012; Morselli et al. 2007; Xu and Chen 2008). ${ }^{11}$

Only two of the studies looked at change in organizational structure over time and both used descriptive statistics; none incorporated dynamic simulation-based models such as exponential random graph models (ERGM). Bright and Delaney (2013) found that as a drug network's profit orientation increases, the structure centralizes and changes from one favoring security to efficiency. They also show that a shift in roles and increase in size favors efficiency over security (study Bright and Delaney 2013). Morselli and Petit (2007) investigated how law enforcement targeting effects the efficiency and security trade-off (study Morselli and Petit 2007). They concluded that as law enforcement targeting and seizures increase, network structure centralizes (density increases) to become more secure.

Eight of the studies assessed the network position of group leaders (studies: Calderoni 2014; Calderoni et al. 2014; Duijn et al. 2014; Hofmann and Gallupe 2015; Malm et al. 2008; Morselli 2009, 2010; Xu and Chen 2008)..$^{12}$ The

\footnotetext{
${ }^{11}$ One study explored internal co-offending (study 16), finding that members of an ethnically diverse, but racially homogeneous street gang were more likely to co-offend with other gang members from the same ethnic group, suggesting the existence of distinct internal co-offending structures.

${ }^{12}$ Notably, several other studies examined group leaders, albeit from different perspectives. For instance, two studies used centrality statistics to help uncover core-periphery structures (studies Baker and Faulkner 1993; Borgatti and Everett 1992) - this perspective argues that within each network a cluster of core actors dominate, and accrue the most benefit, from the network. Adopting a world-system perspective, Boivin (study Boivin 2014) examined the relative position of nations within global drug distribution, comparing cocaine, heroin, and marijuana markets to legitimate trade relations. He found distinct clustering of core nations and greater centralization in cocaine distribution than marijuana. All networks were significantly less dense than legitimate trade networks. Bouchard and Konarski (study Bouchard and Konarski 2014) examined whether a small set of targeted gang members were in fact central to the co-offending network and part of a core group of members; however, only 4 of the 6 most central individuals in the core group were identified by law enforcement. Another set of studies concluded that the central figures in drug markets and groups could be identified using SNA techniques with networks generated from law enforcement and surveillance data (studies Berlusconi 2013; Hutchins and Benham-Hutchins 2010). Notably, Berlusconi (study 1) found that degree and betweenness centrality are robust in identifying key players under conditions of missing data; and, Hutchins and Benham-Hutchins (study Hutchins and Benham-Hutchins 2010) suggest that SNA data mining techniques offer efficient methods for identifying distinct clusters despite low network density and that a small number of highly central brokers (betweenness centrality) are visible. As these studies were not explicitly aiming to examine structure from a security and efficiency perspective they are not included in Table 3.
}

rationale for this focus is that leaders of groups who favor security will seek to protect themselves from the gaze of law enforcement by distancing themselves from others in the group. The results of this research are also mixed. The majority of the studies show that group leaders have both high betweenness and degree centrality, suggesting that they are central actors (studies: Calderoni 2014; Calderoni et al. 2014; Duijn et al. 2014; Hofmann and Gallupe 2015; Tenti and Morselli 2014); however, Morselli (2009, 2010) found that leaders were peripheral to the core of group communication. Incorporating geographic distance with social network metrics, Malm et al. (2008) found that leaders were central in the network, but distanced themselves geographically from drug production sites (study Malm et al. 2008).

As mentioned at the outset of this article, it is important to determine the structural differences of groups operating within the drug market and the market itself. The majority of the studies focused on market structure, including groups and individuals occupying different niches (studies: Calderoni 2014; Calderoni et al. 2014; Mainas 2012; Malm and Bichler 2011; Morselli 2009, 2010; Morselli and Petit 2007; Tenti and Morselli 2014). Only a few studies focused specifically on groups (studies: Bright and Delaney 2013; Hofmann and Gallupe 2015; Morselli et al. 2007; Xu and Chen 2008). The findings indicate little difference between market and group structure. The articles reviewed unanimously show that both groups and networks operating within a drug market expand outward from a core in short chain-like structures, rather than from multiple cells (studies: Calderoni et al. 2014; Duijn et al. 2014; Mainas 2012; Malm and Bichler 2011; Natarajan 2000; Tenti and Morselli 2014; $\mathrm{Xu}$ and Chen 2008). These results also confirm that drug markets conform to small-world properties, ${ }^{13}$ where communication can reach every member of the group with a relatively small number of intermediaries, and network structures are relatively sparse (studies: Mainas 2012; Malm and Bichler 2011; Morselli and Petit 2007; Salazar and Restrepo 2011; Xu and Chen 2008). Generally, these findings are consistent with the results of qualitative research. It follows that law enforcement

\footnotetext{
${ }^{13}$ Networks exhibit small world properties when "global" connectivity patterns generate networks wherein all actors connect to each other through relatively short chains-typically, six or fewer segments connect all actors in the network (e.g., Granovetter 2003; Watts and Strogatz 1998). Illustrating this point with an examination of a Colombian drug trafficking network-Cartel del Norte del Valle-Salazar and Restrepo (study 32 ) document that the average distance between any pair of members was 3.7, in part due to high levels of betweenness. They also found that information shocks, search for threatening nodes, and ultimately, lethal violence flowed through the network in clusters. US policy and major interdiction efforts over the course of 15 years resulted in a decline of centrality and network size, which corresponds with a lengthening of average distance among members from 3.7 to 4.6 .
} 
efforts to disrupt illicit drug trafficking should consider the structure of the target network when developing strategies (e.g., study Malm et al. 2010); however, it is important to be cognizant that their targeting may affect network structure (e.g., study Morselli and Petit 2007).

There is however, a caveat to these findings. There is little consistency in the examined research as to how structural characteristics reflect the concepts of efficiency and security. One group of research finds that high centralization (usually coinciding with lower density) reflects more efficient and less secure networks (studies: Bright and Delaney 2013; Calderoni et al. 2014; Mainas 2012; Malm and Bichler 2011; Morselli et al. 2007). The other group suggests that decreased centralization (increased density) reveals more efficiency and less security (studies: Duijn et al. 2014; Morselli 2010; Morselli and Petit 2007; Salazar and Restrepo 2011). The research focus is one possible source for this contradiction. The former group investigates the natural evolution of drug trafficking groups or compares drug trafficking groups to other groups with notably different objectives and frequency of action; whereas, much of the latter group investigates changing network structure due to increased enforcement activity. Thus, while we see some consistency in the metrics used to describe drug trafficking networks, researchers need to consider the context of networks when applying theory and drawing theoretical conclusions.

\section{Relative importance of social capital versus human capital} Individuals positioned with ties to unique clusters of people have greater social capital (Burt 1992, 1997); however, if we factor for individual attributes and resources, we may find that the role a person plays in the drug distribution process is more telling. Thus, our second focal area is to examine role differentiation and to determine whether the existing SNA literature reveals something about the relative importance of social capital (position within the network) and human capital (access to unique resources and skills) when we attempt to identify critical actors or groups within an illicit drug market. In examining this issue, we ask whether efforts to disrupt market activity gain an advantage by considering these factors. Of the 34 studies looking into the organizational structure of illicit drug trade, 12 examine the social capital of individuals involved in drug market activity by the resources possessed or role they play within a specific group's operation or across a drug distribution chain. ${ }^{14}$ Across the 16 networks described, two SNA metrics are commonly used to assess social capital-degree and betweenness centrality. ${ }^{15}$ The attributes used to reflect human capital are typically associated with operational roles (reported for $87.5 \%$ of the observed networks) or status and/or rank within the group (50\% of the observed networks). Only two studies specifically investigate human capital using actor attributes associated with access to resources and involvement in specific activities.

\section{Operational roles}

While each author used a different set of operational roles to classify drug market participants, evidence is beginning to emerge to suggest that traffickers, those involved in smuggling or organizing shipping consignments, have higher social capital than individuals or groups involved in other roles, for example:

- Examining two case studies, Calderoni (2012, 2014) observed higher average degree and betweenness centrality, but lower clustering coefficients for individuals involved in finding drugs abroad and importing to Italy.

- Investigating all known drug groups working in Western Canada (British Columbia and the Yukon Territory), Malm and Bichler (2011) considered simple involvement (single niche of activity) versus complex activity (participation in two or more operational roles), finding that the people involved in complex transport and complex supply had higher average degree and betweenness centrality scores and low clustering coefficients (study Malm and Bichler 2011).

\footnotetext{
${ }^{14}$ To be included in this analysis, the study must report average scores by role using a graphic or statistic. Notably, we excluded three important studies for this reason. (1) Coding communications about illicit activity for a group of 294 individuals involved in heroin dealing in New York City in the 1990s, Natarajan (2000) maps the organizational structure by role, but does not provide average metrics, nor does she specifically investigate social capital (study Natarajan 2000). (2) Natarajan (2006) examines social power using Bonacichi's power analysis and only reports mean power scores for core members (a group of 38 individuals critical to heroin trafficking) that include sellers, retailers, brokers, and secretaries (study Natarajan 2006) and did not report power scores by role. (3) Garay-Salamanca and SalcedoAlbarán (2012) looked at the social capital of key leaders; however, they did not examine the position or human capital of other members of the three networks investigated.

${ }^{15}$ This widespread use of general centrality measures is a bit surprising given that the originators of social capital theory suggested other metrics to operationalize this concept. For more information about a set of alternative measures of social capital, see Burt $(1992,1997)$
} 
- Studying four mid-level criminal organizations operating in the Spanish cocaine market, Framis (2014) discovered that within each group someone involved with importing/transporting was most central to operations (study Framis 2014).

Notably, only one study explored the social capital of one smuggler throughout their career. Morselli (2001) found that while the network structure varied, at no time was it a hierarchical drug trafficking organization (study Morselli 2001). Arguably, at the most successful period of his trafficking career, the central figure of this network (Mr. Nice) exhibited his greatest level of social capital: highest level of efficiency and lowest effect size-two measures of social capital suggested by Burt $(1992,1997)$. Interestingly, consignments were of medium size (averaging about $3 \mathrm{~kg}$ ) and showed little fluctuation.

Examining group structure and between group crime activities for 9 groups of co-offenders involved in Italian the cocaine market, Tenti and Morselli (2014) discovered that groups occupying the same niche in the drug distribution chain exhibited variation in structure (study Tenti and Morselli 2014). Moreover, highly central individuals were located a different levels of drug distribution; highly central people did not concentrate in a particular role within the industry. Since the configuration of groups varied, so too, did the network resilience among groups. With many partnership agreements approximating a resource-sharing organizational model, the chain-like structure of the network exhibited low density with interacting clusters (subsets) of people.

Only two studies specifically investigate the relative importance of money laundering. Malm and Bichler (2013) find that self-launderers who were also involved in smuggling or supply were the most highly ranked brokers in the network: this is indicative of higher social capital (study Malm and Bichler 2013). Moreover, there were considerably more self-launders found in the network of co-offenders $(82 / 102$ or $80 \%)$ suggesting that with recent technological developments in the financial sector (i.e., hawala banking, bitcoins, person-to-person transfers) money laundering is "de-professionalizing." Morselli and Giguere (2006) add that drug distribution networks include influential participants who appear to work in legitimate occupational settings; of these individuals, those involved in financial activities are critical seeds, introducing others to the network. The authors conclude that these seeds are likely to hold the key to understanding the opportunity structure of criminal enterprise (study Morselli and Giguere 2006).

\section{Access to resources/specialized skills}

Few studies directly examine the relative importance of human capital (access to resources and specialized skills) in comparison to social capital. In a series of studies examining the operations of a methamphetamine trafficking group working out of Australia, Bright and colleagues (studies: Bright et al. 2012, 2014a, b, Bright and Delaney 2013) demonstrate the high correlation between human capital and social capital, where the human capital measure captured a range of tangible and intangible resources. Investigating the market disruption potential of using social and human capital to identify targets for law enforcement action these authors find that degree targeting (individuals with the highest degree centrality) and a mixed identification strategy incorporating human capital and social capital perform the best as gauged by facilitating the greatest reduction in the size of the largest component (group of connected individuals) and maximum disruption of market functionality (study Bright et al. 2014b). These authors, however, caution that law enforcement strategies must remain flexible because people transit in and out of networks causing centrality scores to fluctuate over time (study Bright and Delaney 2013). A point well supported by Duijn et al. (2014).

Testing the simulated effectiveness of a wider range of targeting tactics, Duijn et al. (2014) show that several strategies have the potential to disrupt the Dutch marijuana industry (study Duijn et al. 2014). Comparing five disruption strategies (e.g., random, human capital, degree centrality, betweenness centrality, and human capital and degree centrality) and three recovery mechanisms (e.g., random, preference by social distance or degree centrality), networks were found to exhibit greater density, and thus more resiliency, after attacks targeting those with the most human capital. Moreover, individuals playing instrumental roles were more vulnerable (e.g., coordinators and international traders). These authors assert that disruption strategies must be long term efforts as networks recover to attack in such a manner that they become more efficient and resilient (as discussed earlier in this article).

\section{Discussion \\ Disrupting drug markets}

This study sought to synthesize what we know about the structure of drug trafficking organizations as revealed by SNA scholarship. We reason that qualitative research involving conventional analytic techniques is invaluable to developing ideas about the structure of criminal enterprise, and that to build on this body of work we must apply SNA metrics. By applying SNA metrics, we can standardize how we describe network structures thereby supporting cross-study comparisons about the relative positional importance of people and groups. In doing so, SNA-based research offers a strategy to validate hypotheses in a way that provides direct crime control 
implications. While still in a preliminary stage of development, five implications emerge from this systematic examination of the body of SNA research in this area.

1. Drug trafficking networks are more apt to be sparse with central individuals connecting the group and linking between different groups suggesting an operational preference for security. This result suggests that targeting central individuals may fragment the network (e.g., study Duijn et al. 2014); however, results also suggest there may be a number of individuals waiting to replace central figures. Police need to recognize that increased law enforcement attention will cause the organization to adapt and become more decentralized, thus more difficult to target specific individuals (e.g., study Morselli and Petit 2007). Disruption is a long-term strategy (e.g., studies: Bright et al. 2012, 2014a, b, Bright and Delaney 2013, Duijn et al. 2014).

2. Leaders of drug trafficking networks and those with important roles are identifiable through centrality analysis, if there is sufficient information about group connections (e.g., studies Calderoni et al. 2014; Duijn et al. 2014). Notably, missing or dated information can obscure central actors. Thus, efforts to map criminal networks should regularly extend beyond criminal justice sources to include current affiliations, family connections, and legitimate business relations to ensure the most important actors in the group are correctly identified.

3. Use a range of metrics and analytic techniques to identify central players to target, i.e., spectral embedding (study Calderoni et al. 2014), attributes/roles (studies Bright et al. 2014a, b), meeting participation and communication style (studies: Calderoni 2012; Calderoni 2014), and legitimate connections (study Morselli and Giguere 2006). There are many centrality statistics, each tapping a different aspect of social structure, when combined with decisions about actors and which relations to code, this creates a versatile tool kit through which to understand group structure. Examining the structure from different perspectives will better expose network vulnerabilities.

4. While disruption efforts will vary in effect, degree targeting or degree/human capital strategy performs best. Removing well-positioned and well-resourced actors from the trade network should split the network into smaller components and maximize the potential disruption of market activity (study Bright et al. 2014b). While it is possible to trigger cascading failure with targeted progressive attacks on bridges (study Xu and Chen 2008), the success of crime con- trol policy will depend on the drug market niche that the targeted individual occupies and the complexity of their drug market involvement (study Malm and Bichler 2011). Analysts are advised to identify central actors for each market niche.

5. Map networks repeatedly (over time). Anti-crime strategies need to be flexible as networks continually evolve; attacks on the network, from within due to conflict and launched externally by the criminal justice system, lead to structural evolution. Actors change, centrality scores fluctuate, and roles/attributes adjust (e.g., study Bright and Delaney 2013). Targeting individuals for removal from the network based on human capital stands to increase network density, exposing more of the network as replacement people often create new paths and shortcuts, which raises the efficiency, and inherent resiliency, of the network (e.g., study Duijn et al. 2014). Thus, old network maps are useful as benchmarks against which to assess the efforts of disruption tactics.

At this point, we draw the readers' attention to the methodological shortcomings associated with studying drug trafficking networks.

\section{Research limitations}

Due to three methodological shortcomings, the findings reported above are of limited generalizability. First, as reported in Tables 3 and 4, this body of work primarily uses evidence presented in court or information extracted from police data (intelligence, investigations, or co-arrests). As most researchers using juridical materials to glean network information from electronic surveillance generated during the investigation, police information is the principal data source. ${ }^{16}$ Only one study (study Morselli 2001), explores a network built from an autobiography supplemented with investigatory (DEA electronic surveillance) and news reports. This overreliance on data from the criminal justice system means that we must acknowledge that the efficiency and security tradeoff and the intersection between human and social capital may be different among groups involved in illicit drug trade that do not come to the attention of law

\footnotetext{
${ }^{16}$ Several authors, Varese and Campana (Campana 2011, Campana and Varese 2012, Varese 2011, 2012), Natarajan (studies: Natarajan 2000, 2006), and Calderoni (Calderoni et al. 2014, 2015, and studies: Calderoni 2012, 2014) to name a few, aptly demonstrate the utility of using police data, particularly information gleaned from wiretaps. Berlusconi (2013) supports this research and concludes that structural measures are robust when the data come from a purposive sample of all wiretaps among all criminal network members (study Berlusconi 2013). However, reliance on a single source or type of law enforcement data raises important methodological concerns, namely self-censorship, coverage gaps, unknown network boundaries, limited sample sizes, biased samples, and potential incongruence between the content of the conversation and subsequent action (Varese 2012).
} 


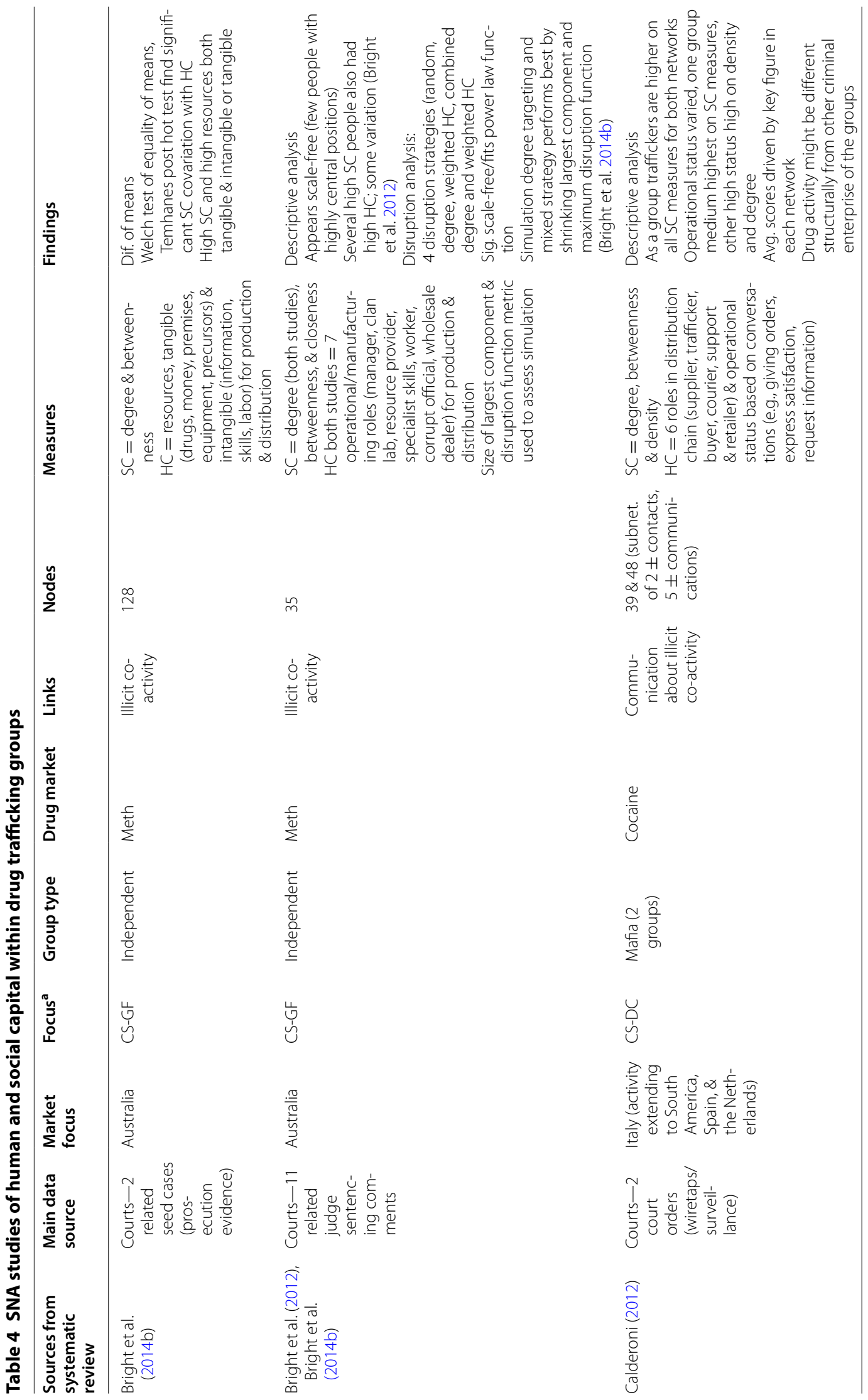




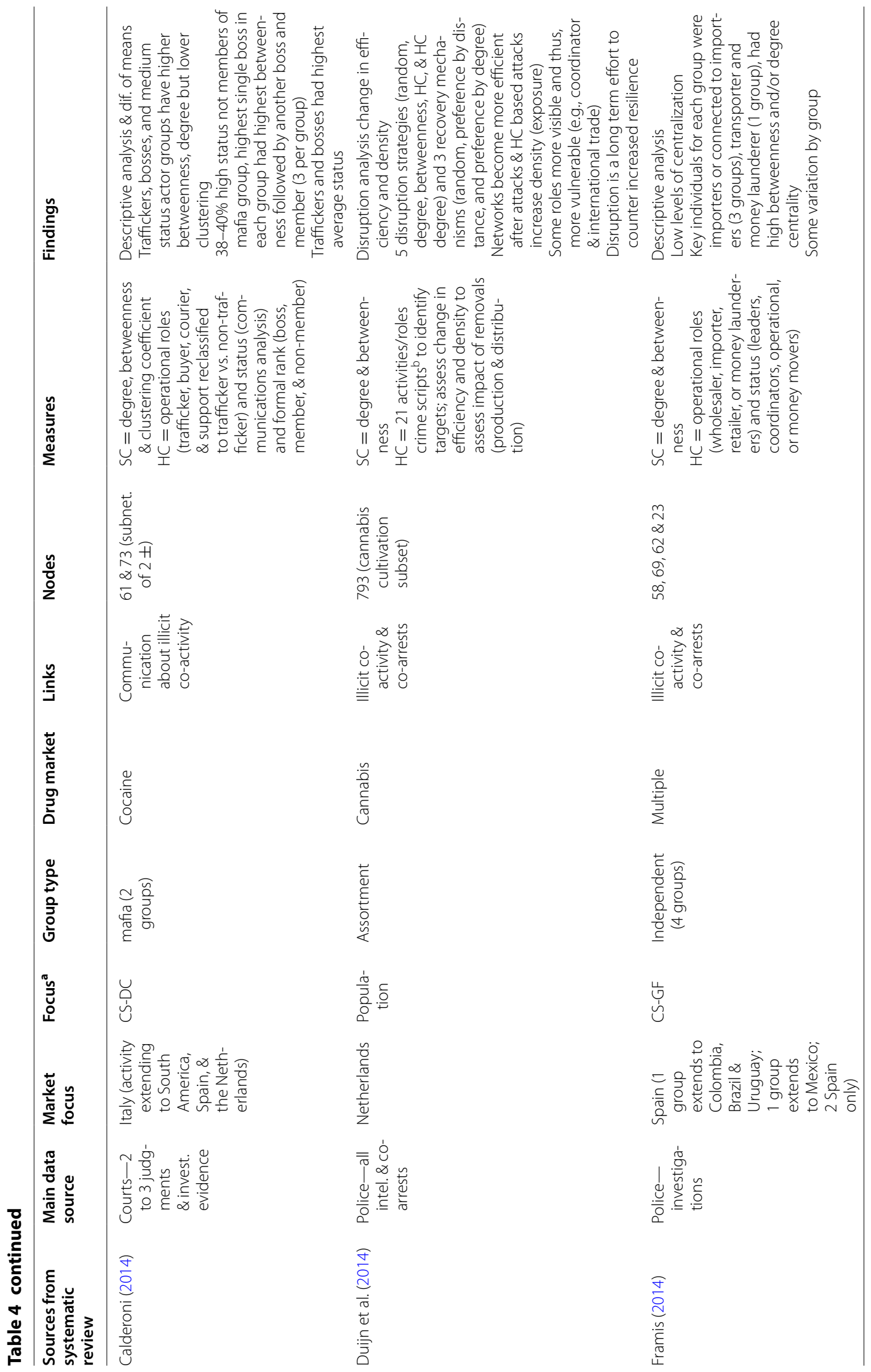




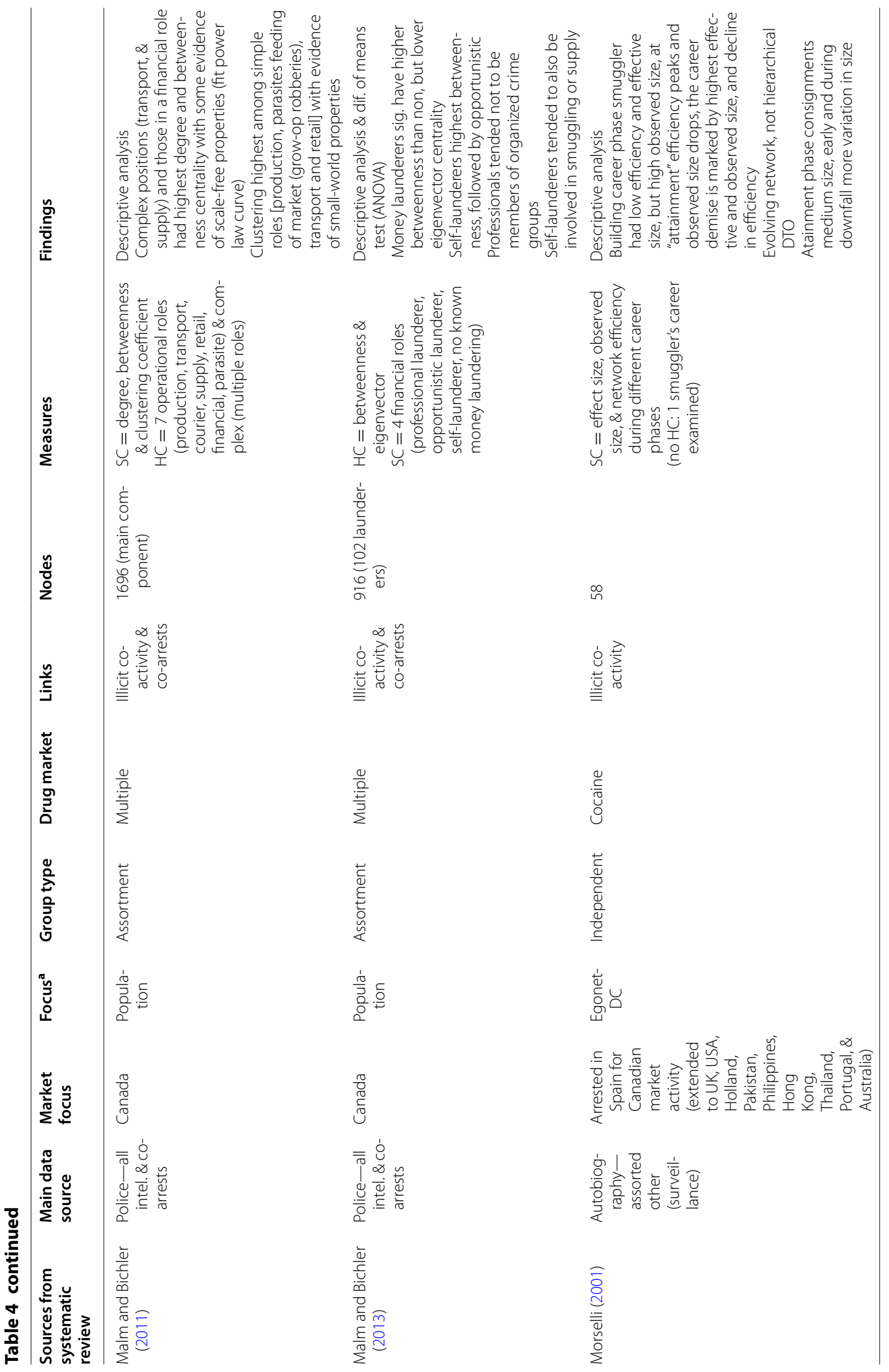




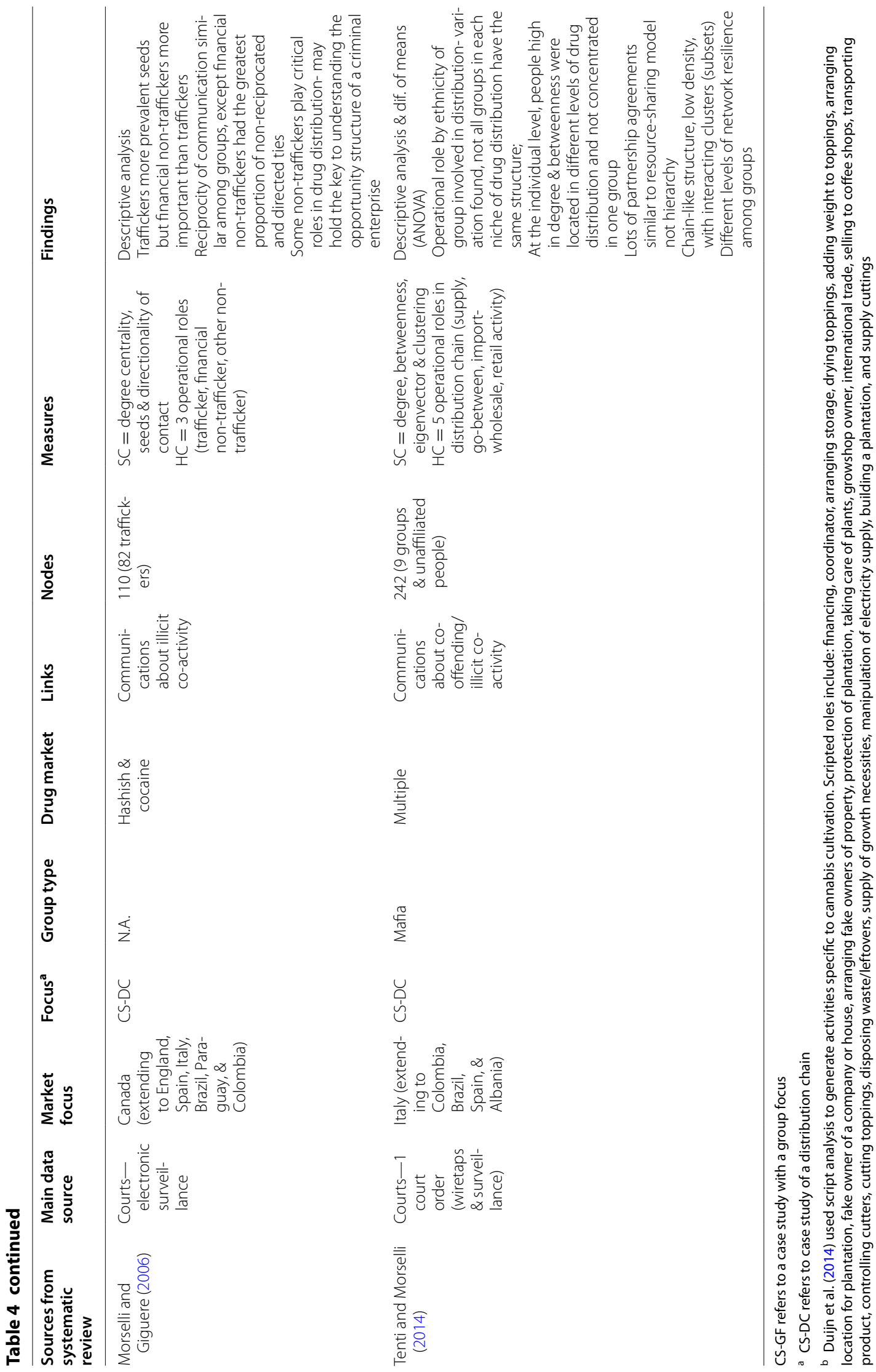


enforcement. Moreover, observed networks may be incomplete, as some actors involved may remain unidentified or mislabeled as being unimportant in the drug trade.

Second, the search strategy used in this systematic review was limited to articles written in English, accessible through a scholarly outlet, and published since 1990 . Therefore, it is quite possible that relevant studies were missed. In this vein, most of these studies examine markets based in Western, consumer nations with extensive coastlines, few shared land borders, and pivotal positions in world trade based on port/shipping activity. ${ }^{17}$ When considered in tandem with the reliance on law enforcement data as discussed above, it is not surprising that the investigatory focus of most of these studies is on groups importing or distributing cocaine and other illicit drugs produced externally. Notable exceptions being Duijn and colleagues (study Duijn et al. 2014) who studied cannabis cultivation in the Netherlands and the research group led by David Bright (studies: Bright et al. 2014a, b; Bright et al. 2012) who investigated the methamphetamine trade in Australia. Being situated as an entrepôrt may affect the capital, human and social, associated with individuals involved in smuggling or transportation roles. Moreover, this context may also unduly accentuate the central positioning of individuals found to be involved in smuggling activity. Had researchers undertaken similar studies in countries with less exposure to the currents of global trade, the organizational structures observed may be considerably different.

The third methodological issue to acknowledge is that most of the observed networks $(76 \%)$ were case studies $-43 \%$ focused on a specific group and 33\% mapped a distribution chain. This disproportional inclusion of purposively selected case studies, chosen in part due to data availability, leads us to conclude that it is premature to suggest that these findings apply to all groups involved in illicit drug trade. With more egocentric and populationbased research, we will be better equipped to assess the generalizability of these case studies.

\section{Advancing the field}

Synthesizing prior research through meta-analyses and systematic reviews is a critical exercise in the advancement of scientific inquiry. Notably, the nascent stage of SNA research in crime science hampered our attempt to synthesize what we know about the organizational structure of illicit drug trade. Reported results were primarily descriptive rather than explanatory, and there

\footnotetext{
${ }^{17}$ Boivin (2014) is a notable exception: His research used drug seizure information for 194 countries reported to the United Nations Office on Drugs and Crime (UNODC) by organizations tasked with monitoring and controlling drug trafficking (study Boivin 2014).
}

was a marked lack of consistency in reporting standards and methods. Moving forward, in order to facilitate cross-case comparison, replication, and rigorous meta-analyses, we suggest that research using social network analysis should incorporate the following reporting standards.

\section{Researchers and analysts must clearly describe how} they generated the networks. Network generation involves making decisions about what constitutes a link between actors and where to obtain information about these connections, as well as whether the relations have an inherent value or directionality. Thus, a clear statement is needed to alert the reader as to what constitutes a tie, the different types of ties (if appropriate), whether ties were valued (or binary), and whether the network was directed (or symmetrical). After generating the initial network, researchers often extract a subsample for analysis (i.e., principal component). A clear explanation of subsample extraction is necessary. It is important to provide these details as decisions made here, may radically influence the results. Even though editorial preferences will relegate some of these details into footnotes, it is important not to cut this information in the final edits. This information reveals how methodological decision-making influences the results and helps to promote replication.

2. Structural differences among groups are often associated with how individuals are connected; thus, investigations must be specific about what constitutes a connection between people (or groups). This means that we should invest more effort into uncovering what the important binding mechanisms are and what advantages different types of bonds have for drug trafficking operations (study Malm et al. 2010), i.e., brokers who do not use violence are more trusted and deeply connected than brokers who do (study Morselli 2001), and family/kinship relations are used for money-laundering and these connections are difficult to sever (studies: Hofmann and Gallupe 2015; Malm and Bichler 2013).

3. Researchers and analysts must describe sampling procedures and how they determined network boundaries. SNA research uses many different sampling strategies, including hybridized techniques using multiple procedures. Even within research using a case-study approach, focal individuals referred to as seeds, are often selected as the starting point around which a network is generated. Using selection criteria, we add individuals to the network based on some type of association with the seed individuals. While most authors often provide this information, they do 
not always explain where the network stops-the network boundary. Conceivably, one could continue for several steps out from a focal individual, i.e., should the friend of a friend of a friend still part of the same group. A pre-determined network boundary should be established and reported. Without these details, replication and cross-study comparison is limited.

4. Irrespective of the stated research objectives, we must report a set of basic descriptive statistics. Due to the novelty of SNA research in criminology, authors tend to devote attention to explaining the metrics used to answer research questions. There are a set of descriptive statistics, however, that provide a framework for understanding structure. Basic descriptive statistics to report include: the number of nodes and links, density, number of components, average path length, average degree, and degree centralization for each network under examination. If a subset is drawn, then two sets of values may be necessary-descriptive statistics for the full network and descriptive statistics for the subset. The scientific method stipulates that basic descriptive statistics are required when reporting results; SNA is not exempt from this foundational tenet.

5. We need to report standardized values for all metrics used to test hypotheses or answer research questions. Network size influences many statistics, and as such, statisticians have developed standardized versions of the key metrics, referred to as normalized values. While raw values have an inherent interpretability, and as such, are widely preferred, study results should also include normalized values where possible (i.e., standardized centrality measures). Reporting normalized values will enable meta-analyses that will advance this field of research.

6. With such a rich body of existing research, replication should take precedence. In what was likely an endeavor to explore the breadth of SNA methods and techniques, scholars in this field examined networks in a variety of ways. Now, the focus can shift to replication, to see if different networks share similar properties when the same analytics are applied. To this end, research collaborations among scholars working in different nations might help to foster more replication and cross-network comparison.

7. It is important to construct titles, select keywords, and write abstracts using standard terms and phrases to ensure that related research is identified, irrespective of search engine used. In this study, we found $26 \%$ of the source articles by reading articles and examining the references listed. Moreover, we had high false positives: wading through hundreds of documents to find a handful of appropriate items is not efficient.
Including standard terms and phrases would improve the research process twofold. First, it will decrease the likelihood of missing important studies when conducting a literature review; and second, standardized language will improve the efficiency of source identification during meta-analyses and systematic reviews.

\section{Conclusions}

Despite the early stage of SNA research in crime science, there are reasons to be optimistic. Data sharing and research collaborations that seek to compare criminal networks are forming. These partnerships often include an international group of scholars who facilitate cross-country network comparisons and a sharing of expertise (i.e., the University of New South Wales Criminal Networks Research Group http://www.cnrg. unsw.edu.au/). Notably, the Illicit Networks Workshop, a working group dedicated to the advancement of a networked criminology, is currently in its eighth year of bringing together scholars from across the world to share ideas and research (Malm and Bichler 2015).

Research funding opportunities for social network research in criminal justice are also emerging. For example, the Violence Reduction Initiative has held webinars bringing together practitioners and academics to educate and share experiences in using SNA for crime reduction. Additionally, the National Institute of Justice has solicited research proposals for the application of SNA to reduce violent crime and increase predictive policing capabilities. We encourage more funding agencies to support research specifically focused on the application of SNA to criminal networks.

In conclusion, while we were limited in our analyses by the lack of standardized reporting and methods used over the 34 studies we reviewed, this systematic review still enables us to answer our three research questions and greatly contributes to the field of organized crime and drug research. The studies included in this review enable us to assert with confidence that drug trafficking networks tend to spread from a relatively dense core in short chain-like structures. The studies also show that these structures are apparent across the drug distribution system. Disruption strategies targeting individuals with high centrality and human capital are likely to include the leaders and other visible members of the drug distribution network, and this should, lead to a more successful crime control.

\section{Authors' contributions}

GB was principal investigator, leading the team of co-authors, AM and TC, who all were involved in executing the study and drafting the manuscript. All authors read and approved the final manuscript. 


\section{Authors' information}

Gisela Bichler is a Professor in the Department of Criminal Justice at California State University, San Bernardino. Generally, Dr. Bichler's research explores the interplay between the environment and offending behavior, using quantitative methodology from social network analysis and crime pattern analysis. Recent publications include the Journal of Research in Crime and Delinquency, Crime and Delinquency, Crime Patterns and Analysis, Global Crime and the Secu rity Journal. She is founder and co-director of the Center for Criminal Justice Research—CSUSB.Email address: gbichler@csusb.edu.

Aili Malm is an Associate Professor in the Department of Criminal Justice at California State University Long Beach. Generally, Dr. Malm's published research centers on the intersection between policing and social policy, concentrating in topics associated with social network analysis. Recent publications include the Journal of Research in Crime and Delinquency, Crime and Delinquency, Crime Patterns and Analysis, Global Crime, and the Security Journal. Email address: amalm@csulb.edu.

Tristen Cooper is a Research Associate with the Center for Criminal Justice Research, California State University, San Bernardino. His research interests include data mining, social network analysis, and national securities studies.

\section{Author details}

${ }^{1}$ Department of Criminal Justice, Center for Criminal Justice Research, California State University, San Bernardino, 5500 University Parkway, San Bernardino, CA 92407, USA. ${ }^{2}$ Department Criminology and Criminal Justice, School of Criminology, Criminal Justice and Emergency Management, California State University, Long Beach, Engineering Technology (ET) Room 232, 1250 Bellflower Blvd., Long Beach, CA 90840, USA. ${ }^{3}$ Center for Criminal Justice Research, California State University, San Bernardino, 5500 University Parkway, San Bernardino, CA 92407, USA

\section{Competing interests}

The authors declare that they have no competing interests.

Received: 28 June 2016 Accepted: 18 January 2017

Published online: 31 January 2017

\section{References}

Adler, P. (1985). Wheeling and dealing: An ethnography of an upper-level drug dealing and smuggling community. New York: Columbia University Press.

Baker, W. E., \& Faulkner, R. R. (1993). The social organization of conspiracy: Illegal networks in the heavy electrical equipment industry. New York, NY: American Sociological Review.

Borgatti, S., \& Everett, M. (1992). Notions of position in social network analysis Social Methods, 22, 1-35.

Borgatti, S., \& Everett, M. (2006). A Graph-theoretic perspective on centrality. Social Networks, 28, 466-484

Burt, R. S. (1992). Structural holes: The social structure of competition. Cambridge: Harvard University Press.

Burt, R. S. (1997). The contingent value of social capital. Administrative Science Quarterly, 42(2), 339-365.

Calderoni, F., Berlusconi, G., Garofalo, L., Giommoni, L., \& Sarno, F. (2015).

The Italian mafias in the world: A systematic assessment of the mobility of criminal groups. European Journal of Criminology. doi:10.1177/1477370815623570.

Campana, P. (2011). Eavesdropping on the Mob: The functional diversification of mafia activities across territories. European Journal of Criminology, 8(3), 213-228.

Campana, P., \& Varese, F. (2012). Listening to the wire: Criteria and techniques for the quantitative analysis of phone intercepts. Trends in Organized Crime, 15, 13-30.

Coleman, J. S. (1988). Social capital in the creation of human capital. American Journal of Sociology, 94, S95-S120.

Dorn, N., Levi, M., \& King, L. (2005). Literature review on upper level drug trafficking. London: Home Office.

Eck, J. E., \& Gersh, J. H. (2000). Drug trafficking as a cottage industry. In M. Natarajan \& M. Hough (Eds.), Illegal drug markets: From research to prevention policy, crime prevention studies (Vol. 11, pp. 241-272). Monsey, NY: Crimina Justice Press.

Freeman, L. F. (1979). Centrality in social networks: Conceptual clarification. Social Networks, 1, 215-239.

Granovetter, M. (1981). The strength of weak ties: A network theory revisited. New York, NY: State University of New York, Department of Sociology.

Granovetter, M. (2003). Ignorance, knowledge, and outcomes in a small world. Science, 301, 773-774

Jackson, J., Herbrink, J. \& Jansen, R. (1996). Examining criminal organizations: Possible methodologies. Transnational Organized Crime, 2(4), 83-105.

Johnson, B. D., Dunlap, E., \& Tourigny, S. C. (2000). Crack distribution and abuse in New York. In M. Natarajan \& M. Hough (Eds.), Illegal drug markets: From research to prevention policy, crime prevention studies (Vol. 11, pp. 19-57). Monsey, NY: Criminal Justice Press.

Kenney, M. (2007). The architecture of drug trafficking: Network forms of organisation in the Colombian cocaine trade. Global Crime, 8, 233-259.

Malm, A., \& Bichler, G. (2015). Seeds of collaboration: The Illicit networks workshop. Journal of Contemporary Criminal Justice, 31(3), 236-242.

Natarajan, M., \& Hough, M. (2000). Illegal drug markets: From research to prevention policy, crime prevention studies (Vol. 11). Monsey, NY: Criminal Justice Press.

Natarajan, M., Zanella, M., \&Yu, C. (2015). Classifying the variety of drug trafficking organizations. Journal of Drug Issues, 45(4), 409-430.

Reuter, P., \& Haaga, J. (1989). The Organization of high-level drug markets: An explorative study. Santa Monica, CA: RAND.

Schneider, Friedrich. (2010). Turnover of organized crime and money laundering: Some preliminary empirical findings. Public Choice, 144, 473-486.

Spapens, T. (2010). Macro networks, collectives, and business processes: An integrated approach to organized crime. European Journal of Crime, Criminal Law and Criminal Justice, 18, 185-215.

Spapens, T. (2011). Interaction between criminal groups and law enforcement: The case of ecstasy in the Netherlands. Global Crime, 12(1), 19-40.

Sparrow, M. S. (1991). The application of network analysis to criminal intelligence: An assessment of the prospects. Social Networks, 13, 251-274

Soudijn, Melvin R. J. (2012). Removing excuses in money laundering. Trends in Organized Crime, 15(2), 146-163.

Soudijn, M. R. J. (2014). Using strangers for money: A discussion on moneylaunderers in organized crime. Trends in Organized Crime, 17, 199-217.

Varese, F. (2011). How mafias take advantage of globalization: The Russian mafia in Italy. British Journal of Criminology, 52(2), 235-253.

Varese, F. (2012). The structure and the content of criminal connections: The Russian mafia in Italy. European Journal of Criminology, 29(5), 899-909.

Watts, D. J., \& Strogatz, S. H. (1998). Collective dynamics of 'small-world' networks. Nature, 393, 440-442.

\section{Sources for systematic review}

Berlusconi, G. (2013). Do all the pieces matter? Assessing the reliability of law enforcement data sources for the network analysis of wire taps. Global Crime, 14(1), 61-81.

Boivin, R. (2014). Drug trafficking networks in the world economy. In C. Morsell (Ed.), Crime and Networks (pp. 182-191). New York, NY: Routledge.

Bouchard, M., \& Konarski, R. (2014). Assessing the core membership of a youth gang from its co-offending network. In C. Morselli (Ed.), Crime and networks (pp. 81-93). New York, NY: Routledge.

Bright, D. A., Greenhill, C., Reynolds, M., Ritter, A., \& Morselli, C. (2014a). The use of actor-level attributes and centrality measures to identify key actors: A case study of an Australian drug trafficking network. Journal of Contemporary Criminal Justice, 31(3), 262-278.

Bright, D. A., \& Delaney, J. J. (2013). Evolution of a drug trafficking network: Mapping changes in network structure and function across time. Global Crime, 14, 238-260

Bright, D. A., Greenhill, C., \& Levenkova, N. (2014b). Dismantling criminal networks: Can node attributes play a role. In C. Morselli (Ed.), Crime and networks (pp. 148-162). New York, NY: Routledge.

Bright, D. A., Hughes, C. E., \& Chalmers, J. (2012). Illuminating dark networks: A social network analysis of an Australian drug trafficking syndicate. Crime, Law and Social Change, 57(2), 151-176.

Calderoni, F. (2012). The structure of drug trafficking mafias: The 'Ndrangheta and cocaine. Crime, Law and Social Change, 58(3), 321-349. 
Calderoni, F. (2014). Strategic positioning in mafia networks. In C. Morselli (Ed.), Crime and networks (pp. 163-181). New York, NY: Routledge.

Calderoni, F., \& Piccardi, C. (2014). Uncovering the structure of criminal organizations by community analysis: The infinito network. 10th international conference on signal-image technology \& internet-based systems (pp. 301-308. doi: 10.1109/SITIS.2014.20.

Calderoni, F., Skillicorn, D., \& Zheng, Q. (2014). Inductive discovery of criminal group structure using spectral embedding. Information \& Security, 31, 49-66.

Canter, D. (2004). A partial order scalogram analysis of criminal network structures. Behaviormetrika, 31(2), 131-152.

Duijn, P. A. C., Kashirin, V., \& Sloot Peter, ma. (2014). The relative ineffectiveness of criminal network disruption. Scientific Reports, 4(4238), 1-15.

Framis, A. (2014). Illegal networks or criminal organizations: Structure, power, and facilitators in cocaine trafficking structures. In C. Morselli (Ed.), Crime and Networks (pp. 131-147). New York, NY: Routledge.

Garay-Salamanca, L. J., \& Salcedo-Albarán, E. (2012). Institutional impact of criminal networks in Colombia and Mexico. Crime Law and Social Change, $57,177-194$.

Grund, T. U., \& Densley, J. A. (2012). Ethnic heterogeneity in the activity and structure of a black street gang. European Journal of Criminology, 9(4), 388-406.

Hofmann, D. C., \& Gallupe, O. (2015). Leadership protection in drug trafficking networks. Global Crime, 16(2), 123-138.

Hutchins, C. E., \& Benham-Hutchins, M. (2010). Hiding in plain sight: Criminal network analysis. Computational and Mathematical Organizational Theory, $16,89-111$.

Mainas, E. D. (2012). The analysis of criminal and terrorist organizations as social network structures: A quasi-experimental Study. International Journal of Police Science and Management, 14(3), 264-282.

Malm, A., \& Bichler, G. (2011). Networks of collaborating criminals: Assessing the structural vulnerability of drug markets. Journal of Research in Crime and Delinquency, 48(2), 271-297.

Malm, A., \& Bichler, G. (2013). Using friends for money: The positional importance of money-launderers in organized crime. Trends in Organized Crime, 16(4), 365-381.
Malm, A., Bichler, G., \& Van De Walle, S. (2010). Comparing ties that bind criminal networks: Is blood thicker than water? Security Journal, 23, 52-74.

Malm, A., Kinney, J. B., \& Pollard, N. (2008). Social network and distance correlates of criminal associates involved in illicit drug production. Security Journal, 21, 77-94.

Morselli, C. (2001). Structuring Mr. Nice: Entrepreneurial opportunities and brokerage positioning in the cannabis trade. Crime, Law and Social Change, $35,203-244$.

Morselli, C. (2009). Hells angels in springtime. Trends in Organized Crime, 12, $145-158$.

Morselli, C. (2010). Assessing vulnerable and strategic positions in a criminal network. Journal of Contemporary Criminal Justice, 26(4), 382-392.

Morselli, C., \& Giguere, C. (2006). Legitimate strengths in criminal networks. Crime, Law \& Social Change, 45, 185-200.

Morselli, C., \& Petit, K. (2007). Law-enforcement disruption of a drug importation network. Global Crime, 8(2), 109-130.

Morselli, C., Giguère, C., \& Petit, K. (2007). The efficiency/security trade-off in criminal networks. Social Networks, 29, 143-153.

Natarajan, M. (2000). Understanding the structure of a drug trafficking organization: A conversational analysis. In M. Natarajan \& M. Hough (Eds.), Illegal drug markets: From research to prevention policy, crime prevention studies (Vol. 11, pp. 273-298). Monsey, NY: Criminal Justice Press.

Natarajan, M. (2006). Understanding the structure of a large heroin distribution network: A quantitative analysis of qualitative data. Journal of Quantitative Criminology, 22(2), 171-192.

Salazar, B., \& Restrepo, L. M. (2011). Lethal closeness: The evolution of a smallworld drug trafficking network. Desafios, 23(2), 197-221.

Tenti, V., \& Morselli, C. (2014). Group co-offending networks in Italy's illegal drug trade. Crime, Law and Social Change, 62, 21-44.

$\mathrm{Xu}, \mathrm{J}$, \& Chen, H. (2008). The topology of dark networks. Communications of the ACM, 51(10), 58-65.

\section{Submit your manuscript to a SpringerOpen ${ }^{\circ}$ journal and benefit from:}

- Convenient online submission

- Rigorous peer review

- Immediate publication on acceptance

- Open access: articles freely available online

- High visibility within the field

- Retaining the copyright to your article

Submit your next manuscript at $\boldsymbol{\nabla}$ springeropen.com 